\title{
Detection of Sugar-Regulated Gene Expression and Signaling in Suspension-Cultured Rice Cells
}

\author{
Shin-Lon Ho \\ Department of Agronomy, National Chiayi University, Chiayi, Taiwan \\ Email: slho@mail.ncyu.edu.tw
}

How to cite this paper: Ho, S.-L. (2018) Detection of Sugar-Regulated Gene Expression and Signaling in Suspension-Cultured Rice Cells. American Journal of Plant Sciences, 9, 1124-1142. https://doi.org/10.4236/ajps.2018.96085

Received: April 4, 2018

Accepted: May 14, 2018

Published: May 17, 2018

Copyright $\odot 2018$ by author and Scientific Research Publishing Inc. This work is licensed under the Creative Commons Attribution International License (CC BY 4.0).

http://creativecommons.org/licenses/by/4.0/ (c) (i) Open Access

\begin{abstract}
To better understand the mechanism of sugar signaling in rice cell, the suspension-cultured rice cells were transferred from sucrose-containing $(+S)$ to sucrose-free $(-S)$ of MS culture medium, we found that ribosomal RNAs (rRNAs) were degraded progressively. This suggests that carbon, nitrogen, and phosphate were recycled in this process and the reduction in cellular rRNAs might lead to decreased translation to save energy in response to sugar starvation. Differential screening revealed that two groups of genes, sugar-starvation-repressed (SSR) and sugar-starvation-activated (SSA) genes, were regulated by sugar in an opposing manner. Northern-blot analysis showed that two major hybridization signals of 0.8 and $1.9 \mathrm{~kb}$ were induced strongly under sugar starvation. The two populations of genes corresponded with homologs of $\alpha$-amylases (1.9 kb) and the glycine-rich proteins (GRPs) gene family $(0.8 \mathrm{~kb})$, and all were SSA genes. Expression of GRP genes was strongly induced in sugar-starved cells, which suggests that GRPs may help to protect cells against nutritional stress. Treatment of $+S$ and $-S$ cells with the protein kinase $(\mathrm{PK})$ inhibitor staurosporine $(\mathrm{St})$ and the serine/theronine phosphoprotein phosphatases 1 (PP1) and 2A (PP2A) inhibitor okadaic acid (OA) revealed that PP1 and PP2A (PPs) might be involved in increasing SSR gene expression in $+S$ cells, and that activation of the majority of the SSA genes in $-S$ cells might be due to PKs activity. These results suggested that PKs and PPs might be involved in the sugar regulation of SSR and SSA gene expression. An in-gel PK activity assay demonstrated that the activity of two classes of PKs (50 and $66 \mathrm{kDa}$ ) may be induced rapidly after transfer of $+S$ cells to $-S$ medium. Following transfer of $-S$ cells to $+S$ medium, a novel class of $38 \mathrm{kDa}$ PK was induced rapidly and showed high activity. The $38 \mathrm{kDa} \mathrm{PK}$ might play a role in sugar sensing, and the 50 and $66 \mathrm{kDa}$ PKs might play roles in signal sensing under sugar starvation in rice cells. These results provide valuable information on three classes of protein kinases that might play key roles in sugar sensing and signaling in rice.
\end{abstract}




\section{Keywords}

Suspension-Cultured Rice Cells, Glycine-Rich Proteins, Sugar-Starvation Repressed, Sugar-Starvation Activated, Protein Kinases, Phosphoprotein Phosphatases

\section{Introduction}

Carbohydrates are important nutrients in metabolism and important structural constituents in plants. Sugars, which are the basic units of carbohydrates, can serve as an energy source or a synthetic building block. Sugar availability may determine the direction of cellular metabolism and developmental responses [1] [2]. Many studies indicate that the expression of a variety of genes is regulated by sugar. In rice suspension-cultured cells, two sets of genes, namely growth-related and stress-related genes, are up- and down-regulated, respectively, by sugars [3]. In general, sugars favor the expression of genes in connection with the biosynthesis, respiration, and storage of reserves, and conversely repress the expression of genes associated with photosynthesis and reserve mobilization [4] [5]. For example, sugars positively regulate the expression of genes that encode storage proteins, such as patatin in potato and sporamin in sweet potato [6] [7]. Accumulation of the mRNAs that encode proteins associated with starch biosynthesis, such as ADP glucose pyrophosphorylase, is also dependent on sugars [8]. In contrast, a variety of genes involved in key metabolic processes are negatively regulated by sugars, such as $\alpha$-amylase in rice [9] [10], and the ribulose 1,5-bisphosphate carboxylase/oxygenase small subunit $(r b c S$ ) and chlorophyll $a / b$ binding protein $(\mathrm{Cab})$ in maize protoplasts and suspension-cultured Chenopodium cells [11] [12]. A GeneChip analysis detected transcriptional up-regulation of 343 genes in sugar-starved suspension-cultured Arabidopsis cells [13]. These genes are involved in the recycling of cellular components and nutrient scavenging, in a variety of defense and stress-response pathways, with specific protein kinases and transcription factors regulating these processes.

One of the most extensively studied sugar-regulated genes in plants is that for $\alpha$-amylase. Expression of the gene is induced by sugar deprivation in suspension-cultured rice cells, germinating embryos, and aleurone layers, and is suppressed by addition of sucrose [9] [10]. Sugar repression of $\alpha$-amylase gene expression is reported to involve the control of both transcription and mRNA stability [14] [15] [16]. All $\alpha$-amylase genes isolated from a variety of plant species contain a TATCCA element, or variants, in the promoter region, to which MYB nuclear proteins bind in a sequence-specific and sugar-dependent manner [5] [17] [18]. Transient expression assays with barley half-seeds showed that OsMYBS1 and OsMYBS2 activate a promoter containing the TATCCA element when sugar is added. With sugar starvation, OsMYBS3 represses transcription of the same promoter [19]. However, the details of sugar signaling pathways in plants require clarification. 
Many studies indicate that hexokinase acts as the primary sugar sensor [1] [20] [21] [22] [23] [24]. In Arabidopsis, antisense suppression and overexpression of AtHXK1 resulted in insensitivity and hypersensitivity to exogenous glucose, respectively [20]. Other sugar-sensing pathways in plants have been proposed, such as hexose-dependent but hexokinase-independent, and sucrose-dependent pathways [21] [25] [26] [27] [28] [29]. Moreover, a gene (SnRK1) that encodes the yeast SNF1 homolog was cloned from potato and shown to be required for activation of sucrose synthase gene expression [30]. The expression of antisense SnRK1 in wheat embryos represses the activity of an $\alpha$-amylase gene promoter, which suggests that SnRK1 is required for activation of glucose-repressing genes [31]. Rice SnRK1A functions upstream of the interaction between the transcription factor MYBS1 and a sugar response complex in the $\alpha A m y 3$ promoter to relieve glucose repression [32]. These results suggest that SnRK1 plays a role in sugar signal reception. An additional molecule involved in sugar signaling is trehalose 6-phosphate (T6P), which is generated from glucose 6-phosphate and UDP-glucose by trehalose 6-phosphate synthase (TPS) [33]. Overexpression of AtTPS1 in Arabidopsis results in insensitivity to glucose during seed germination [34], and increased quantities of T6P represses SnRK1 activity [35], which suggests that T6P and SnRK1 play contrasting roles in sugar responses.

In this study, we quantified the effect of sugar on cellular transcripts, and observed a high proportion of GRP homologs induced in suspension-cultured rice cells under sugar starvation. We showed that the protein kinase (PK) inhibitor staurosporine (St) and protein phosphatase (PP) inhibitor okadaic acid (OA) differentially affected the expression of genes subject to sugar-mediated regulation. Notably, addition or withdrawal of sugar from the culture medium resulted in rapid and transient activation of the specific activity of 38,50, and $66 \mathrm{kDa}$ PKs, which indicates that PKs may perform important roles in sugar sensing in rice.

\section{Materials and Methods}

\subsection{Plant Material}

The rice cultivar Oryza sativa L. cv Tainung 67 was used. Immature seeds were dehulled, sterilized with $2.4 \% \mathrm{NaOCl}$ for $1 \mathrm{~h}$, washed thoroughly with sterile water, and placed on N6D agar medium for callus induction. After 1 month, the callus derived from scutella was transferred to liquid Murashige and Skoog (MS) medium [36] supplemented with 3\% sucrose and $10 \mu \mathrm{M}$ 2,4-Dichlorophenoxyacetic acid (2, 4-D, a synthetic plant hormone auxin, which is necessary for rice cell division) to establish a suspension cell culture. Cells were cultured on a reciprocal shaker at $120 \mathrm{rpm}$ and incubated at $26^{\circ} \mathrm{C}$ in the dark.

\subsection{Differential Screening of cDNA Library}

Suspension-cultured rice cells were subcultured in fresh MS medium supple- 
mented with sucrose $(+S)$ and cultured for $72 \mathrm{~h}$, then the cells were transferred to sucrose-free $(-S)$ medium for $4 \mathrm{~h}$ to isolate the candidate genes in response to sugar signaling in earlier phase. The cells were harvested and total RNA was purified. Poly $(\mathrm{A})^{+}$RNA was purified from the total RNA using an oligo (dT)-cellulose spin column. The Poly $(A)^{+}$RNA was used to construct a cDNA library with the $\lambda$ gt $22 \mathrm{~A}$ vector and the SuperScript ${ }^{\mathrm{tm}}$ II reverse transcriptase cDNA library construction system (Invitrogen, Carlsbad, CA, USA). The pool of

${ }^{32} \mathrm{P}$-labeled single-stranded cDNA probes were prepared from Poly $(\mathrm{A})^{+} \mathrm{RNA}$ derived from $24 \mathrm{~h}$ of $+\mathrm{S}$ or $-\mathrm{S}$ cells, respectively, using an oligo (dT) primer and SuperScript ${ }^{\mathrm{TM}}$ II reverse transcriptase. Duplicated filters prepared from high-density platings of the cDNA library were differentially screened with the differential cDNA probes. The phage plaques that showed hybridization signals strongly associated with the cDNA probes from $24 \mathrm{~h}-\mathrm{S}$ cells and weakly associated with the cDNA probes from $24 \mathrm{~h}+\mathrm{S}$ cells were isolated. The cDNAs inserted in the $\lambda$ gt22A vector were cleaved with $N o t$ and $S a l l$ and subcloned into the NotI-Sall sites of pBluescript vectors before being subjected to sequencing analysis.

\subsection{Plasmids}

The inserted DNA fragments of $A c t, A D H 2, G 3 P D, H S P 86$, and SSP2 were digested from the pBluescript vector with SaII and NotI. The DNA fragments of salT, OsGRP1, OsGRP2, OsGRP3, OsGRP4, and OsGRP5 were digested with $E c o$ RI. The $\alpha A m y 3$ and $\alpha A m y 8$ gene-specific DNA fragments were prepared as described by Sheu et al. [15]. The inserted DNAs were individually isolated, labeled with ${ }^{32} \mathrm{P}$, and used as probes. A DNA fragment containing the $28 \mathrm{~S}, 18 \mathrm{~S}$, and 5.8S rDNAs was excised from the pRY18 plasmid using BamHI, labeled with $\alpha^{-}{ }^{32} \mathrm{P}$, and used as a probe to evaluate the quantity of the rRNA.

\subsection{Northern-Blot Analysis}

Total RNA was isolated from suspension-cultured cells using the TRIzol Reagent (Invitrogen). The RNA gel-blot was analyzed as described by Ho et al. [3] . Ten micrograms of total RNA was electrophoresed in $1 \%$ agarose gel containing $10 \mathrm{mM}$ sodium phosphate buffer ( $\mathrm{pH}$ 6.5), transferred to a nylon membrane, and hybridized with random-primer-labeled $\left[\alpha-{ }^{32} \mathrm{P}\right] \mathrm{dCTP}$ cDNA probes at $42^{\circ} \mathrm{C}$. The membranes were exposed to X-ray film at $-80^{\circ} \mathrm{C}$.

\subsection{In-Gel Protein Kinase Activity Assay}

Rice suspension-cultured cells were harvested and ground into powder. Proteins were purified with precooled extraction buffer (50 mM Hepes. $\mathrm{KOH}$ [pH 7.6], 1 mM EDTA, 1 mM EGTA, $10 \mathrm{mM} \mathrm{NaF}, 1 \mathrm{mM} \mathrm{Na}_{3} \mathrm{VO}_{4}, 1 \mathrm{mM} \mathrm{Na}_{3} \mathrm{MoO}_{4}, 20 \mathrm{mM}$ $\beta$-glycerophosphate, $20 \%$ glycerol, $2 \mathrm{mM} \mathrm{DTT}$, and $2 \mathrm{mM} \mathrm{PMSF}$ ), supplemented with $2 \mu \mathrm{g} / \mathrm{mL}$ of three different protease inhibitors, namely leupeptin, E64, and pepstatin. After thorough mixing and centrifugation at $18,000 \times g$ for $10 \mathrm{~min}$, 
the supernatants were collected and the protein concentration was quantified using the method of Bradford [37]. The in-gel PK activity assay was conducted in accordance with the methods of Mizoguch et al. [38] and Usami et al. [39] with minor revision. In brief, $50 \mu \mathrm{g}$ proteins were separated by $10 \%$ SDS-PAGE with or without $0.5 \mathrm{mg} / \mathrm{mL}$ histone III-S (Sigma). After electrophoresis, the gel was rinsed in the wash solution $(20 \% \beta$-propanol and $50 \mathrm{mM}$ Tris- $\mathrm{HCl}[\mathrm{pH} 8.0]$ for $1 \mathrm{~h}$ to remove SDS, followed by soaking with buffer containing $50 \mathrm{mM}$ Tris- $\mathrm{HCl}(\mathrm{pH} 8.0$ ) and $5 \mathrm{mM} \beta$-mercaptoethanol for removal of $\beta$-propanol residues. The gel was denatured at $25^{\circ} \mathrm{C}$ for $2 \mathrm{~h}$ with denaturation solution (6 M guanidine hydrochloride, $50 \mathrm{mM}$ Tris- $\mathrm{HCl}[\mathrm{pH} 8.0]$ and $5 \mathrm{mM} \beta$-mercaptoethanol), then renatured at $4^{\circ} \mathrm{C}$ for at least $16 \mathrm{~h}$ by neutralization solution $(50 \mathrm{mM}$ Tris- $\mathrm{HCl}[\mathrm{pH} 8.0], 5 \mathrm{mM} \beta$-mercaptoethanol, and $0.04 \%$ Tween 40 ). For kinase activity detection, the gel was soaked in kinase reaction buffer (40 mM Hepes. $\mathrm{KOH}$ [pH 7.6], $2 \mathrm{mM}$ DTT, $15 \mathrm{mM} \mathrm{MgCl}, 30$ mM ATP, $100 \mu C i\left[\gamma_{-}^{-32} \mathrm{P}\right] \mathrm{ATP}$, and $\left.0.1 \mathrm{mM} \mathrm{EGTA}\right)$ and incubated at $25^{\circ} \mathrm{C}$ for 1 $\mathrm{h}$, then rinsed in stop solution (5\% TCA and $1 \%$ sodium pyrophosphate) for 30 min to terminate the reaction. The gel was washed several times with sterilized water to remove the free isotope, then the gel was vacuumed dried and exposed to X-ray film.

\section{Results}

\subsection{Sugar Modulates Ribosomal RNA Turnover}

Carbon metabolite-regulated gene expression is known in a variety of living organisms. Gene expression, through the processes of mRNA transcription followed by protein translation by the ribosome in accordance with the coding sequence of mRNA, results in biologically active polypeptides. Ribosomal RNA (rRNA) is the main component of the cellular ribosome and constitutes more than $80 \%$ of the total cellular RNA. Therefore, the rRNAs may be used as a measure of total mRNA stability. In addition, suspension-cultured cells represent a convenient experimental system with which to study mechanisms involved in gene regulation owing to their sensitivity of responses to exogenous stimuli. We therefore used suspension-cultured rice cells and rRNA to dissect the global changes in total RNA stability in the presence or absence of exogenous sucrose in the culture medium. The suspension cells were cultured in sucrose-containing $(+\mathrm{S})$ medium for $72 \mathrm{~h}$, then transferred to sucrose-free $(-\mathrm{S})$ medium for $72 \mathrm{~h}$ to let sugar was depleted completely in cells, followed by provision with sucrose for $24 \mathrm{~h}$. Total RNA was purified from these cells at specific time points (Figure 1) and subjected to northern-blot analysis using rDNA (a rice genomic rDNA cluster, including the $18 \mathrm{~S}, 5.8 \mathrm{~S}$, and $28 \mathrm{~S}$ rRNA genes) as a probe. As shown in Figure 1(a), after RNA electrophoresis, when cells were transferred to $-\mathrm{S}$ medium, the amount of small RNAs gradually increased from time 0 to $12 \mathrm{~h}$ (lanes $5-10$, the position indicated by arrowhead), dramatically increased at $24 \mathrm{~h}$ (lane 11), and peaked at $36-72 \mathrm{~h}$ (lanes $12-14$ ). Accumulation of the small RNAs progressively decreased $24 \mathrm{~h}$ after the transfer of cells from $-\mathrm{S}$ 


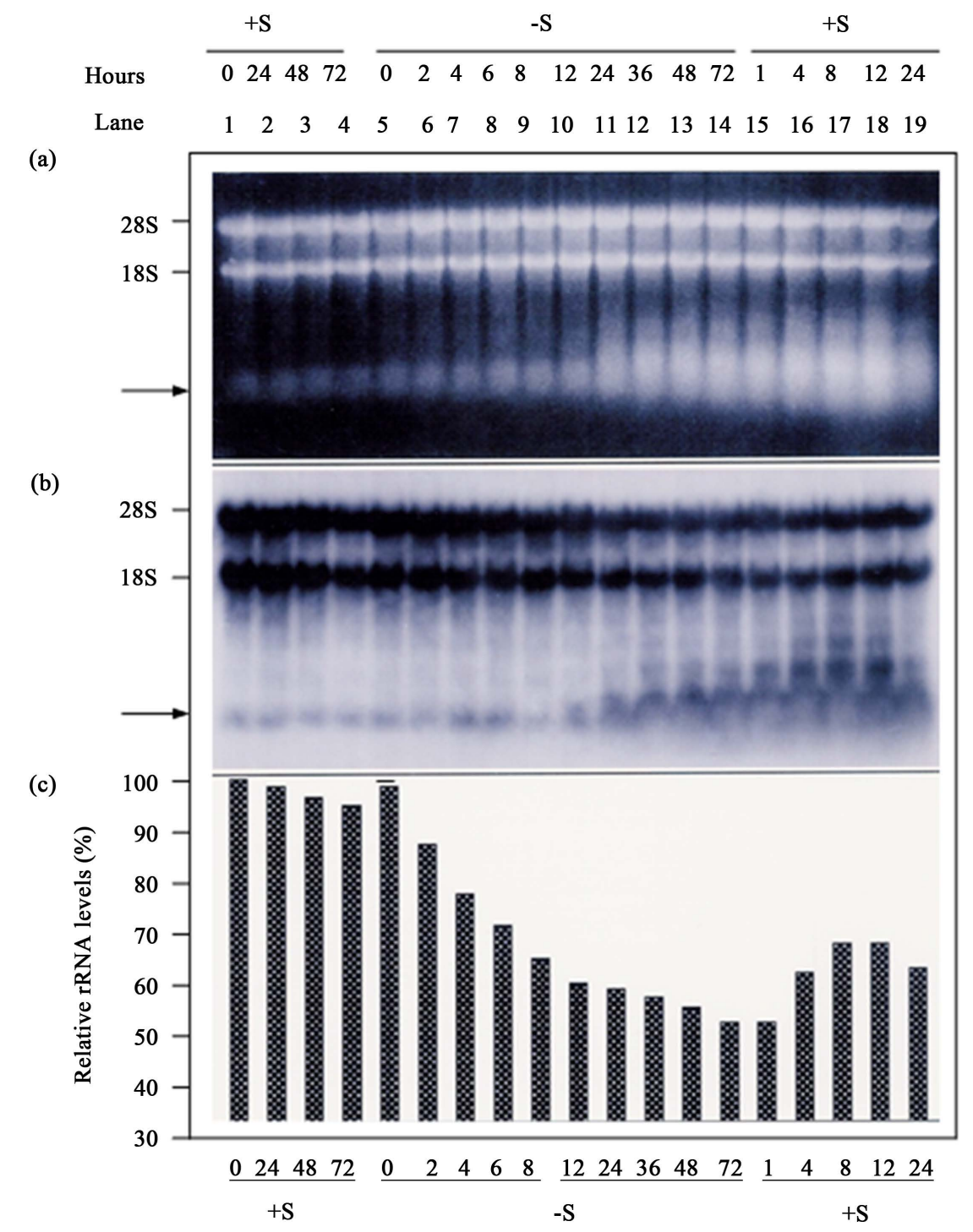

Figure 1. Increased rRNA degradation in rice suspension-cultured cells under sucrose starvation. After incubation for $72 \mathrm{~h}$ in sucrose-containing $(+\mathrm{S})$ medium, cells were transferred to sucrose-free $(-S)$ medium for $72 \mathrm{~h}$, and then transferred to $+S$ medium for an additional $24 \mathrm{~h}$. Total RNA was purified from the cells and agarose gel electrophoresis was conducted. (a) After electrophoresis, the gel was stained with ethidium bromide and photographed; (b) The gel blot was hybridized with a ${ }^{32} \mathrm{P}$-labeled rDNA probe; (c) Levels of $28 \mathrm{~S}$ and $18 \mathrm{~S}$ rRNAs were quantified using a PhosphorImager (Molecular Dynamics, Sunnyvale, CA, USA). The positions of $28 \mathrm{~S}$ and $18 \mathrm{~S}$ rRNAs are as indicated. Arrows indicate the position of RNA degradation products.

to $+S$ medium (lane 19). These small RNAs hybridized with the rDNA probe, which suggests that their accumulation was derived from the degradation products of rRNAs (Figure 1(b)). These results are also supported by quantitative estimation of the concentration of remaining intact rRNAs using phosphor-imaging software (Figure $1(\mathrm{c})$ ). After cells were transferred from $+S$ to $-S$ medium, in contrast to small RNAs, the accumulation of rRNAs progressively decreased (-S, $0-48 \mathrm{~h}$ ), attaining the lowest level $72 \mathrm{~h}$ after sugar starvation, and 
progressively increased after cells were transferred from $-\mathrm{S}$ to $+\mathrm{S}$ medium. These results suggest that reduction in the amount of rRNAs might be due to increased degradation rather than decreased synthesis during sucrose starvation. Given that rRNAs are functionally correlated with protein synthesis, reduction in cellular rRNAs content probably leads to reduction in translation to conserve energy in response to sugar starvation.

\subsection{Global Gene Expression in Sugar-Starved Cells}

To evaluate global gene expression in rice cells under sugar starvation, total RNA was purified from suspension-cultured rice cells treated with or without sugar and subjected to northern-blot hybridization. The total poly $\left(\mathrm{A}^{+}\right) \mathrm{RNA}$ (mRNA) was prepared from cells cultured in $+\mathrm{S}$ or $-\mathrm{S}$ medium for $24 \mathrm{~h}$. The purified mRNA was used as the template to synthesize the pool of $\left[\alpha-{ }^{32} \mathrm{P}\right]$-labeled cDNA probes. Two major hybridization signals were distinctly induced in cells under sugar-starvation treatment (Figure 2, indicated by arrows). One induction signal was similar in size to that of $18 \mathrm{~S}$ rRNA $(1.9 \mathrm{~kb})$, which was induced abundantly when cells were starved of sucrose for $48-72 \mathrm{~h}$ and declined rapidly $1-4 \mathrm{~h}$ after cells were transferred from $-\mathrm{S}$ to $+\mathrm{S}$ medium. The other signal was about $0.8 \mathrm{~kb}$ in size. The mRNA populations gradually accumulated and attained the highest amounts at 12 - $72 \mathrm{~h}$ after sugar starvation (lanes 10 - 14) and rapidly decreased 1 - $24 \mathrm{~h}$ after transfer to culture medium supplemented with sucrose (lanes 15 - 19). These results suggested that the two distinct populations of 1.9 $\mathrm{kb}$ and $0.8 \mathrm{~kb}$ mRNAs might play important roles in the response to sugar starvation in rice cells.

To verify the two populations of corresponding genes induced under sugar starvation, differential screening of a cDNA library prepared from rice cells sugar-starved for $4 \mathrm{~h}$ was conducted. After screening, more than $100 \mathrm{cDNA}$

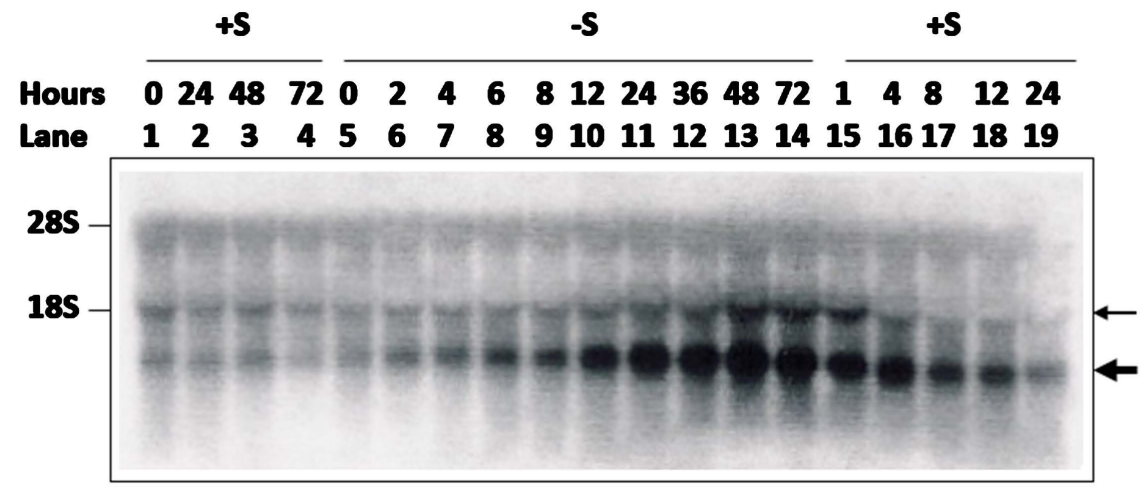

Figure 2. Northern-blot analysis of global gene expression in rice suspension cells cultured in sucrose-containing $(+S)$ or sucrose-free $(-S)$ medium. Total RNA isolation and gel electrophoresis was performed as described in the legend of Figure 1. After blotting, the membrane was hybridized with the pool of ${ }^{32} \mathrm{P}$-labeled single-stranded cDNA probes, which were prepared from Poly $(\mathrm{A})^{+}$RNA derived from cells cultured under sugar starvation for $24 \mathrm{~h}$, using an oligo (dT) primer and reverse transcriptase. The thin and thick arrows indicate the positions of 1.9 and $0.8 \mathrm{~kb}$ RNAs, respectively. 
clones that showed stronger signals (spots) after hybridization with either the pool of $-S$ or $+S$ cDNA probes were selected (Supplementary Figure S1) and cloned into plasmid vectors. Among these cDNA clones, five clones showed strongest hybridization signals with the $+\mathrm{S}$ cDNA probes and a weak signal with the $-S$ cDNA probes (defined as the sugar-starvation-repressed [SSR] genes), and 12 clones showed stronger hybridization signals with the $-\mathrm{S}$ cDNA probes (defined as the sugar-starvation-activated [SSA] genes). These 17 cDNA clones were partially sequenced and analyzed. As described in our previous study [3], the five SSR cDNA clones were identified as actin (Act), alcohol dehydrogenase 2 (ADH2), glyceraldehyde-3-phosphate dehydrogenase (G3PD), heat shock protein 86 (HSP86) and sucrose synthase P2 (SSP2), and the corresponding full-length cDNA clones were obtained from the Japan Rice Genome Research Program [40]. Among the 12 SSA cDNA clones, three clones were $\alpha$-amylase homologous genes (two clones were $\alpha A m y 3$ [XM_015794560, the predicted mRNA length in GenBank was $1834 \mathrm{bp}$, one clone was $\alpha A m y 8$ [XM_015795212, the predicted mRNA length was $1687 \mathrm{bp}]$ ), and one clone was identical to $s a l T$ (S45168, $724 \mathrm{bp}$ ). Unexpectedly, the other eight clones were highly homologous to the glycine-rich proteins (GRPs) gene family of unknown function, of which three identical clones were designated OsGRP1 (X54449, predicted mRNA length in GenBank was 834 bp), two clones were OsGRP2 (D21281, $852 \mathrm{bp}$ ), and one clone each as OsGRP3 (AF010579, 713 bp), OsGRP4 (U40708, $551 \mathrm{bp}$ ) and OsGRP5 (AJ002893, $780 \mathrm{bp}$ ). The predicted mRNA lengths of all the isolated SSA clones were consistent with the two major hybridization signals detected by $-S$ cDNA probes at the positions of higher molecular weight (corresponding to the length of $\alpha A m y 3$ and $\alpha A m y 8$ ) (Figure 2, thin arrow) or lower molecular weight (this position similar to the length of GRPs and salT) (Figure 2 , thick arrow). These results suggest that the expression of a high proportion of $\alpha$-amylase and GRP homologs was induced abundantly during sugar starvation.

We verified whether the isolated clones that showed gene expression patterns affected by sugar were also involved in protein phosphorylation and protein dephosphorylation events. The rice cells were cultured in $+S$ medium for $72 \mathrm{~h}$, then transferred to $+S$ or $-S$ medium without exogenous treatment and further incubated for $2 \mathrm{~h}$ and $12 \mathrm{~h}$ (Figure 3 and Figure 4, lanes 1 - 4), respectively, or exogenous supplementation with either the PK inhibitor staurosporine (St) (Figure 3 and Figure 4, lanes $5-8$ ) or the serine/theronine phosphoprotein phosphatases 1 (PP1) and 2A (PP2A) inhibitor okadaic acid (OA) (Figure 3 and Figure 4, lanes 9 - 12), and cultured for an additional $2 \mathrm{~h}$ and $12 \mathrm{~h}$, respectively. Cells were collected and total RNA was purified and subjected to northern-blot hybridization by using the 3 '-untranslated region (3'-UTR) of the examined gene as a gene-specific probe. The accumulation of all five SSR genes was increased in cells cultured in $+S$ medium, but was repressed in cells cultured in $-S$ medium (Figure 3, cf. lanes 2 and 4). Furthermore, expression of each of the predicted SSA genes was more strongly activated in cells cultured for $12 \mathrm{~h}$ in $-\mathrm{S}$ medium than in cells cultured in $+S$ medium for $12 \mathrm{~h}$ (Figure 4, cf. lanes 2 and 4 ). These 


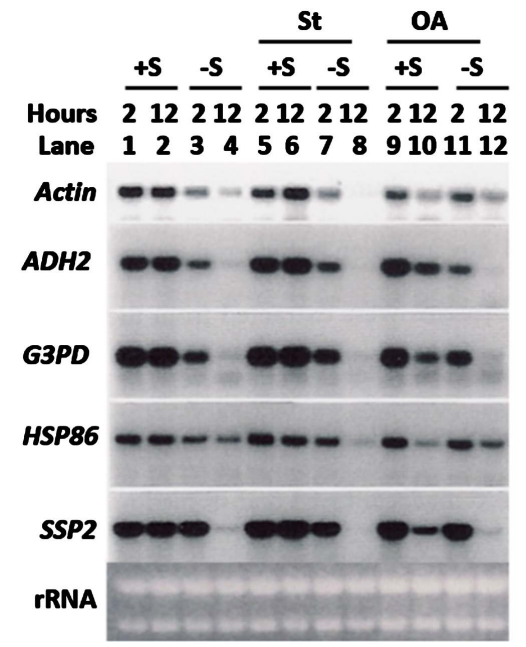

Figure 3. Protein kinase and protein phosphatase inhibitors alter expression of sucrose-starvation-repressed genes. Rice suspension cells were cultured in sucrose-containing $(+S)$ medium for $72 \mathrm{~h}$ and transferred to $+\mathrm{S}$ or sucrose-free $(-\mathrm{S})$ medium lacking an inhibitor, or treated with the protein kinase inhibitor staurosporine $(2 \mu \mathrm{M}$; St), or the phosphoprotein phosphatase 1 (PP1) and 2A (PP2A) inhibitor okadaic acid (100 nM; OA), and incubated for an additional 2 or $12 \mathrm{~h}$. All media contained $0.2 \%$ dimethyl sulforide (DMSO), which was used to dissolve St and OA. Total RNA was purified and subjected to RNA gel blot analysis. Sucrose-starvation-repressed genes were used as probes. Act, actin; $\mathrm{ADH} 2$, alcohol hydrogenase 2; G3PD, glyceraldehydes-3-phosphate dehydrogenase; HSP86, heat shock protein 86; SSP2, sucrose synthase P-2; $\alpha$ Amy, $\alpha$-amylase.

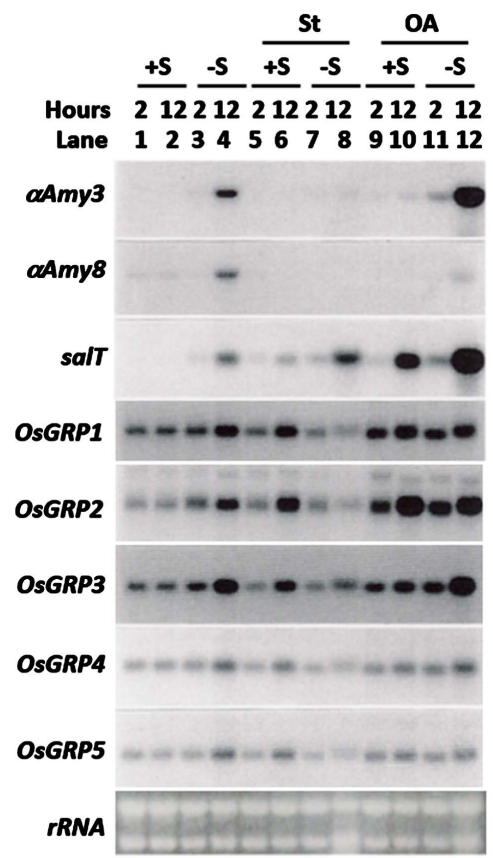

Figure 4. Protein kinase and protein phosphatase inhibitors alter expression of sucrose-starvation-activated genes. The treatment of rice suspension-cultured cells and the gel blotting procedure was identical to that described in the legend of Figure 3. The blotted membranes were hybridized with the probes prepared from the 3 '-untranslated gene-specific regions of the sucrose-starvation-activated genes. $\alpha$ Amy, $\alpha$-amylase; GRP, glycine-rich protein. 
findings indicate that the expression of all SSA clones was sensitive to sugar content in the culture medium and was activated in $-\mathrm{S}$ cells, whereas activation was diminished in $+S$ cells, and the expression patterns are all converse in those SSR genes. Therefore, the SSR and SSA genes were considered to be an ideal sample to study the regulatory mechanisms of sugar regulation pathways.

\subsection{Protein Kinase and Protein Phosphatase Effects on the Sugar Regulation of Gene Expression}

In the present study, we observed that two groups of genes (SSR and SSA genes) were regulated by sugar in opposing manners. To further verify whether the effects of sugar were mediated by protein phosphorylation or dephosphorylation, suspension-cultured rice cells treated with PK or PP inhibitors were subjected to northern-blot analysis. In $+S$ cells, accumulation of mRNAs of all five SSR genes was not affected by St (Figure 3, cf. lanes 2 and 6), but was repressed by OA (Figure 3, cf. lanes 2 and 10). In -S cells, the mRNA level for all of the SSR genes was repressed by St (Figure 3, cf. lanes 4 and 8), but was not altered by OA (Figure 3, cf. lanes 4 and 12). On the basis of these results, the activity of PPs may positively regulate SSR gene expression in $+S$ cells, whereas the activity of PKs somewhat activated expression of SSR genes in $-S$ cells.

In $+S$ cells, St slightly activated the expression of SSA genes, but not that of $\alpha A m y 3$ and $\alpha A m y 8$ (Figure 4, cf. lanes 2 and 6). In contrast, OA dramatically increased the expression of salT, OsGRP1, OsGRP2, and OsGRP3, and slightly activated OsGRP4 and OsGRP5. No effect of OA on $\alpha A m y 3$ and $\alpha A m y 8$ was observed (Figure 4, cf. lanes 2 and 10). In -S cells, St enhanced expression of salT but suppressed that of the other seven SSA genes (Figure 4, cf. lanes 4 and 8). Okadaic acid enhanced the expression of $\alpha A m y 3$, salT, OsGRP2, and OsGRP3, but suppressed $\alpha A m y 8$ expression. Okadaic acid had no effect on expression of OsGRP1, OsGRP4, and OsGRP5 (Figure 4, cf. lanes 4 and 12). On the basis of these results, in $+\mathrm{S}$ cells the activities of both PKs and PPs may suppress the expression of SSA genes, but not that of $\alpha A m y 3$ and $a A m y 8$. In $-S$ cells, the activity of some PKs may negatively regulate the expression of salT and positively regulate expression of other SSA genes. Some PPs suppressed the expression of $\alpha A m y 3$, salT, OsGRP2, and OsGRP3, but activated the expression of $\alpha A m y 8$, and no effect on the expression of OsGRP1, OsGRP4, and OsGRP5 was observed. These results suggest that PKs, PP1, and PP2A might be involved in the regulation of SSR and SSA gene expression by sugars.

\subsection{Detection of Protein Kinase Activity Involved in Sugar Sensing}

To determine the types of PKs that may be involved in sugar signaling in rice cells, an in-gel PK activity assay was conducted. Rice suspension cells were cultured in $+S$ medium for $72 \mathrm{~h}$, then the culture was divided into two equal portions: one portion was transferred to fresh $+S$ medium, and the other portion was transferred to $-\mathrm{S}$ medium; each portion was cultured for $24 \mathrm{~h}$. The cells 
cultured in $+S$ medium were then transferred to either $+S$ or $-S$ medium, and cultured for an additional 5, 10, 20, and 60 min (Figure 5(a)). Similarly, the cells cultured in $-S$ medium were then transferred to either $+S$ or $-S$ medium, and cultured for an additional 1, 2, 5, and 10 min (Figure 5(b)). The cells were harvested at the specified time points and total proteins were purified for the in-gel PK activity assay by supplementation with (Figure 5(a) and Figure 5(b), upper panel) or without (Figure 5(a) and Figure 5(b), lower panel) Histone III-S in the gel as the PK substrate. We therefore could distinguish the signals of PKs activity derived from autophosphorylation of PKs (without Histone III-S in gel) (Figure 5, lower panel) or phosphorylation of the substrate by the specific PK activity (with Histone III-S in gel) (Figure 5, upper panel). After the $+S$ cells were transferred to $+S$ medium, no obvious difference in the specific signal of PKs activity was detected, nor in the presence or absence of Histone III-S in the gel (Figure 5(a)). However, after cells were transferred from $+S$ to $-S$ medium, two specific signals of PKs activity, one stronger signal located in the position of about $66 \mathrm{kDa}$ and a weaker signal at about $50 \mathrm{kDa}$, were induced rapidly within $5-10 \mathrm{~min}$, and thereafter declined quickly and were only weakly detected at 20 min (Figure 5(a), lanes 6 - 9). Moreover, four constitutive PKs activity detected

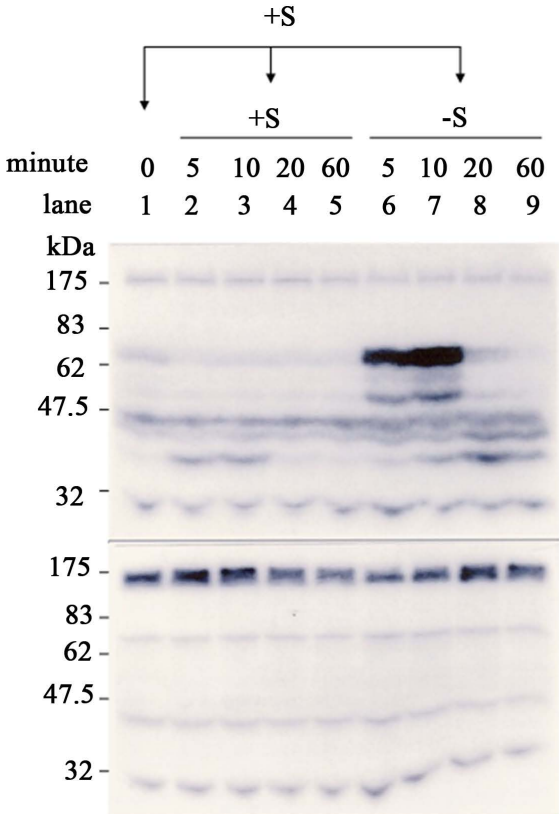

(a)

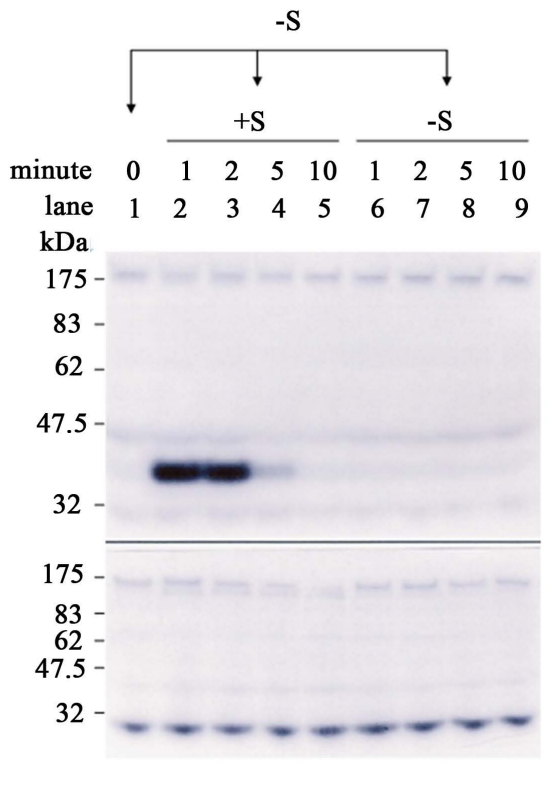

(b)

Figure 5. Activation of protein kinases in response to alteration in sucrose level. Rice suspension cells were cultured in sucrose-containing $(+S)$ medium for $72 \mathrm{~h}$, then transferred to $+S$ or sucrose-free $(-S)$ medium for $24 \mathrm{~h}$, and followed by transfer to fresh $+S$ or $-S$ medium for the indicated time periods. Proteins were extracted from the harvested cells and subjected to an in-gel protein kinase activity assay by addition of histone III-S in the gel as a substrate. (a) Cells transferred from $+S$ medium to $+S$ or $-S$ medium; (b) Cells transferred from $-S$ medium to $+S$ or $-S$ medium. Upper panel: with addition of exogenous histone III-S in the gel as a substrate. Lower panel: without addition of histone III-S in the gel as the control. 
at the positions of about $30,45,66$, and $170 \mathrm{kDa}$, irrespective of $+\mathrm{S}$ and $-\mathrm{S}$ cells and with or without Histone III-S in the gel (Figure 5), revealed that at least four classes of autophosphorylation of PKs were exhibited in rice cells. Similar to the experimental results shown in Figure 5(a), after $-S$ cells were transferred to $+S$ and $-S$ medium followed by incubation for an additional 5, 10, 20, and $60 \mathrm{~min}$, only a weaker signal was detected specifically at the position of about $38 \mathrm{kDa}$ at 5 min after the transfer of $-\mathrm{S}$ cells to $+\mathrm{S}$ medium. This result indicates that activity of the $38 \mathrm{kDa}$ PK may be induced rapidly within $5 \mathrm{~min}$. We therefore shortened the incubation time points to $1,2,5$, and $10 \mathrm{~min}$ after $-\mathrm{S}$ cells were transferred to $+S$ and $-S$ medium. As shown in Figure 5(b), after $-S$ cells were transferred to $+\mathrm{S}$ medium, we observed that a strong signal of PKs activity was induced rapidly at the position of $38 \mathrm{kDa}$, and that no inducible signal of PKs activity was observed after $-S$ cells were transferred to $-S$ medium. Altogether, the present results demonstrate that activity of two classes of PKs, of 50 and $66 \mathrm{kDa}$, were induced after $+S$ rice cells were transferred to $-S$ medium, and activity of a $38 \mathrm{kDa}$ class of $\mathrm{PK}$ was induced after $-\mathrm{S}$ cells were transferred to $+\mathrm{S}$ medium. These results indicate that the $38 \mathrm{kDa}$ class of $\mathrm{PK}$ might play a role in sugar sensing, and that the 50 and $66 \mathrm{kDa}$ classes of PKs might play roles in signal transduction of sugar starvation in rice cells.

\section{Discussion}

Sugars can modulate gene expression at the transcriptional and post-transcriptional levels through a complex signal transduction network and through certain common mechanisms [3]. Many reviews summarize evidence for sugar control of gene expression through the activities of a variety of protein kinases, protein phosphatases, transcription factors, and cis-acting regulatory elements [5] [21] [22] [24] [27] [29]. Sugars also show interactions with light, stress, and phytohormone signaling pathways. In Arabidopsis suspension-cultured cells, the mRNA levels of 343 genes increase in response to sugar starvation [13]. Three of these genes were identified as putative GRPs. Interestingly, the three genes respectively showed a 33-, 23-, and 96-fold increase in transcript level after $24 \mathrm{~h}$ of sugar starvation [13]. The present study reveals that a group of low-molecular-weight mRNAs (about $0.8 \mathrm{~kb}$ ) showed a dramatic increase in expression after $12-72 \mathrm{~h}$ of sugar starvation, and the expression decreased after the cells were provided with sugar (Figure 2). Eight of 12 cDNA clones showed expression patterns similar to that of the low-molecular-weight mRNAs, and all were highly homologous to GRPs. These findings are consistent with those of Conteno et al. [13] and may explain the high proportion of GRP genes cloned in sugar-starved cells. The GRPs are widely distributed in plants, of which some are developmentally regulated and some are involved in response to stresses, such as wounding, virus infection, drought, and flooding [41] [42] [43] [44] [45]. Sugar starvation is a severe nutritional stress in a plant cell, and during this condition many symptoms may be exhibited to conserve and supply energy, such as retarded cell division 
and growth, autophagy, reduced protein synthesis, and strong activation of $\alpha$-amylase and proteolytic enzymes [29]. Similar to the aforementioned studies, the present results show that extension of the duration of sugar starvation of rice cells was accompanied by global degradation of rRNAs and mRNAs (Figure 1), which might be intended to supplement the nitrogen and carbon sources in the cell. Moreover, two populations of mRNAs, namely those of $\alpha$-amylases and GRPs, were induced and expressed abundantly during 12 - $72 \mathrm{~h}$ of sugar starvation, which suggests that $\alpha$-amylases and GRPs might play important roles in the response to sugar starvation (Figure 2). The $\alpha$-amylases hydrolyze starch into glucose to provide a carbon source [5]. Although GRPs form a group of structural protein components in the cell walls of many higher plants [46] [47], the biological functions of GRPs in response to biotic and abiotic stresses in plant cells is still largely unknown. We observed that under the energy-limited condition of sugar starvation, a population of GRPs is still generated, which suggests that GRPs might play novel roles in adaptation or response to nutritional stress in plant cells. In addition, the synchronized induction and repression of $G R P$ homologs in $-S$ and $+S$ cells, respectively (Figure 3 and Figure 4), might imply that a common signaling pathway is operational in sugar sensing. Given that $G R P$ transcript levels are synergistically regulated and sensitive to sugar supply, GRPs be a useful indicator in investigations of the sugar signaling pathway.

One of the most advanced studies of sugar signaling in plants is on the hexokinase-dependent pathway [22]. In Arabidopsis, phosphorylation of mannose by hexokinase leads to the repression of genes needed for germination, but capability for germination can be restored by a specific hexokinase inhibitor, mannoheptulose [48]. Transgenic Arabidopsis plants that carry the antisense hexokinase are hyposensitive to sugar and show normal development comparable to that of the wild type, whereas plants that overexpress hexokinase are hypersensitive to sugar, leading to developmental arrest in the seedling [20]. In maize protoplasts and suspension-cultured cells of Chenopodium rubrum, incorporation of OA (a PP1 and PP2A inhibitor) in $-\mathrm{S}$ medium may mimic the repression of photosynthesis gene expression by sugars [49] [50]. These results reveal that protein phosphorylation and dephosphorylation events are involved in the sugar signal transduction pathway. In $+S$ cells, we observed that the sugar-induced expression of SSR genes was repressed by OA (Figure 3). In addition, St and OA may diminish the effects of sugar-induced suppression of SSA gene expression (Figure 4). In $-\mathrm{S}$ cells, neither St nor OA altered the expression of SSR genes (Figure 3). In contrast, we observed that St repressed expression of SSA genes but enhanced expression of salT. Okadaic acid enhanced the effect of sugar starvation on $\alpha A m y 3$, salT, OsGRP2, and OsGRP3 mRNA levels, but reduced the $-\mathrm{S}$ induction of $\alpha A m y 8$ expression (Figure 4 ). These findings suggest that in $+\mathrm{S}$ cells, PKs and PPs coordinately down-regulate expression of SSA genes, but not that of $\alpha A m y 3$ and $\alpha A m y 8$. In $-S$ cells, the expression of all GRP homologs was coordinately up- and down-regulated by PKs and PPs, respec- 
tively. Interestingly, although $\alpha A m y 3$ and $\alpha A m y 8$ are homologous genes, the expression of $\alpha A m y 3$ and $\alpha A m y 8$ may be coordinately up-regulated by PKs, whereas PPs differentially down- and up-regulate the expression of $\alpha A m y 3$ and $\alpha A m y 8$, respectively. These results demonstrate that sugar signaling pathways function via a complex crosstalk between phosphorylation and dephosphorylation to control expression of a variety of genes.

In signaling transduction pathways, the signaling molecules usually stimulate a rapid, transient response, and the effects can be rapidly reversed [51]. Consistent with this observation, the present results demonstrated that activity of two classes of PKs, of 50 and $66 \mathrm{kDa}$, was induced rapidly 5 - $10 \mathrm{~min}$ after transfer of $+\mathrm{S}$ rice cells to $-\mathrm{S}$ medium, and the induced signals were almost non-detectable 20 min after transfer (Figure 5(a)). Moreover, when $-\mathrm{S}$ cells were transferred to $+\mathrm{S}$ medium for 1 - 2 min, a novel class of $38 \mathrm{kDa} \mathrm{PK}$ was hypersensitive to sugar and high activity was induced immediately, but then declined quickly and almost vanished at $5 \mathrm{~min}$ after transfer (Figure 5(b)). These results suggest that the $38 \mathrm{kDa}$ PK class might play a role in sugar sensing, and the 50 and $66 \mathrm{kDa}$ PK classes might play roles in signal sensing in response to sugar starvation in rice cells. To the best of our knowledge, no known class of PK is induced rapidly and is highly expressed in response to sugar and sugar-starvation signaling in plant cells. These results provide valuable information that indicates that 38,50 and $66 \mathrm{kDa}$ protein kinases might play key roles as sensors in sugar sensing and signaling.

\section{Conclusion}

Our results provided novel information that a population of glycine-rich proteins might play important roles in response to sugar starvation in rice cells. And a class of $38 \mathrm{kDa}$ protein kinases could act as a sugar sensor, and the class of 50 and $66 \mathrm{kDa}$ protein kinases might function as a sensor in response to sugar starvation in rice cells.

\section{Acknowledgements}

This work was supported by grants from the Ministry of Science and Technology of the Republic of China (Grant Nos. MOST 105-2313-B-415-009- and MOST 106-2313-B-415-006-).

\section{References}

[1] Granot, D., David-Schwartz, R. and Kelly, G. (2013) Hexose Kinases and Their Role in Sugar-Sensing and Plant Development. Frontiers in Plant Science, 4, 44. https://doi.org/10.3389/fpls.2013.00044

[2] Lastdrager, J., Hanson, J. and Smeekens, S. (2014) Sugar Signals and the Control of Plant Growth and Development. Journal of Experimental Botany, 65, 799-807. https://doi.org/10.1093/jxb/ert474

[3] Ho, S.L., Chao, Y.C., Tong, W.F. and Yu, S.M. (2001) Sugar Coordinately and Differentially Regulates Growth and Stress-Related Gene Expression via a Complex 
Signal Transduction Network and Multiple Control Mechanisms. Plant Physiology, 125, 877-890. https://doi.org/10.1104/pp.125.2.877

[4] Koch, K.E. (1996) Carbohydrate-Modulated Gene Expression in Plants. Annual Review of Plant Physiology and Plant Molecular Biology, 47, 509-540.

https://doi.org/10.1146/annurev.arplant.47.1.509

[5] Yu, S.M. (1999) Cellular and Genetic Responses of Plants to Sugar Starvation. Plant Physiology, 121, 687-693. https://doi.org/10.1104/pp.121.3.687

[6] Jefferson, R., Goldsbrough, A. and Bevan, M. (1990) Transcriptional Regulation of a Patatin-1 Gene in Potato. Plant Molecular Biology, 14, 995-1006.

https://doi.org/10.1007/BF00019396

[7] Hattori, T., Nakagawa, S. and Nakamura, K. (1990) High Level Expression of Tuberous Root Storage Protein Genes of Sweet Potato in Stems of Plantlets Grown in Vitro on Sucrose Medium. Plant Molecular Biology, 14, 595-604. https://doi.org/10.1007/BF00027505

[8] Müller-Röber, B.T., Kobmann, J., Hannah, L.C., Willmitzer, L. and Sonnewald, U. (1990) One of Two Different ADP-Glucose Pyrophosphorylase Genes from Potato Responds Strongly to Elevated Levels of Sucrose. Molecular Genetics and Genomics, 224, 136-146.

[9] Yu, S.M., Kuo, Y.H., Sheu, G., Sheu, Y.J. and Liu, L.F. (1991) Metabolic Derepression of $\alpha$-Amylase Gene Expression in Suspension-Cultured Cells of Rice. Journal of Biological Chemistry, 266, 21131-21137.

[10] Yu, S.M., Lee, Y.C., Fang, S.C., Chan, M.T., Hwa, S.F. and Liu, L.F. (1996) Sugar Act as Signal Molecules and Osmotica to Regulate the Expression of $\alpha$-Amylase Genes and Metabolic Activities in Germinating Cereal Grains. Plant Molecular Biology, 30, 1277-1289. https://doi.org/10.1007/BF00019558

[11] Krapp, A., Hofmann, B., Schäfer, C. and Stitt, M. (1993) Regulation of the Expression of $r b c S$ and Other Photosynthetic Genes by Carbohydrates: A Mechanism for the "Sink Regulation" of Photosynthesis? The Plant Journal, 3, 817-828. https://doi.org/10.1111/j.1365-313X.1993.00817.x

[12] Sheen, J. (1990) Metabolic Repression of Transcription in Higher Plants. The Plant Cell, 2, 1027-1038. https://doi.org/10.1105/tpc.2.10.1027

[13] Contento, A.L., Ki, S.J. and Bassham, D.C. (2004) Transcriptome Profiling of the Response of Arabidopsis Suspension Culture Cells to Suc Starvation. Plant Physiology, 135, 2330-2347. https://doi.org/10.1104/pp.104.044362

[14] Sheu, J.J., Jan, S.P., Lee, H.T. and Yu, S.M. (1994) Control of Transcription and mRNA Turnover as Mechanisms of Metabolic Repression of $\alpha$-Amylase Gene Expression. The Plant Journal, 5, 655-664. https://doi.org/10.1111/j.1365-313X.1994.00655.x

[15] Sheu, J.J., Yu, T.S., Tong, W.F. and Yu, S.M. (1996) Carbohydrate Starvation Stimulates Differential Expression of Rice $\alpha$-Amylase Genes That Is Modulated through Complicated Transcriptional and Posttranscriptional Processes. Journal of Biological Chemistry, 271, 26998-27004. https://doi.org/10.1074/jbc.271.43.26998

[16] Chan, M.T. and Yu, S.M. (1998) The 3'-Untranslated Region of a Rice $\alpha$-Amylase Gene Functions as a Sugar-Dependent mRNA Stability Determinant. Proceedings of the National Academy of Sciences of the United States of America, 95, 6543-6547. https://doi.org/10.1073/pnas.95.11.6543

[17] Hwang, Y.S., Karrer, E.E., Tomas, B.R., Chen, L. and Rodriguez, R.L. (1998) Three Cis-Elements Required for Rice $\alpha$-Amylase Amy3D Expression during Sugar Starvation. Plant Molecular Biology, 36, 331-341. 
https://doi.org/10.1023/A:1005956104636

[18] Lu, C.A., Lim, E.K. and Yu, S.M. (1998) Sugar Response Sequence in the Promoter of a Rice $\alpha$-Amylase Gene Serves as a Transcriptional Enhancer. Journal of Biological Chemistry, 273, 10120-10131. https://doi.org/10.1074/jbc.273.17.10120

[19] Lu, C.A., Ho, T.H.D., Ho, S.L. and Yu, S.M. (2002) Three Novel MYB Proteins with One DNA Binding Repeat Mediate Sugar and Hormone Regulation of $\alpha$-Amylase Gene Expression. The Plant Cell, 14, 1963-1980. https://doi.org/10.1105/tpc.001735

[20] Jang, J.C. and Sheen, J. (1997) Sugar Sensing in Higher Plants. Trends in Plant Science, 2, 208-213. https://doi.org/10.1016/S1360-1385(97)89545-3

[21] Sheen, J., Zhou, L. and Jang, J.C. (1999) Sugars as Signaling Molecules. Current Opinion in Plant Biology, 2, 410-418. https://doi.org/10.1016/S1369-5266(99)00014-X

[22] Rolland, F., Moore, B. and Sheen, J. (2002) Sugar Sensing and Signaling in Plants. The Plant Cell, 14, S185-S205. https://doi.org/10.1105/tpc.010455

[23] Moore, B., Zhou, L., Rolland, F., Hall, Q., Cheng, W.H., Liu, Y.X., et al. (2003) Role of the Arabidopsis Glucose Sensor HXK1 in Nutrient, Light, and Hormonal Signaling. Science, 300, 332-336.

[24] Rolland, F., Baena-Gonzalez, E. and Sheen, J. (2006) Sugar Sensing and Signaling in Plants: Conserved and Novel Mechanisms. Annual Review of Plant Biology, 57, 675-709.

[25] Smeekens, S. and Rook, F. (1997) Sugar Sensing and Sugar-Mediated Signal Transduction in Plants. Plant Physiology, 115, 7-13. https://doi.org/10.1104/pp.115.1.7

[26] Halford, N.G., Purcell, P.C. and Grahame, H.D. (1999) Is Hexokinase Really a Sugar Sensor in Plants? Trends in Plant Science, 4, 117-120. https://doi.org/10.1016/S1360-1385(99)01377-1

[27] Smeekens, S. (2000) Sugar-Induced Signal Transduction in Plants. Annual Review of Plant Physiology and Plant Molecular Biology, 51, 49-81. https://doi.org/10.1146/annurev.arplant.51.1.49

[28] Hanson, J. and Smeekens, S. (2009) Sugar Perception and Signaling-An Update. Current Opinion in Plant Biology, 12, 562-567. https://doi.org/10.1016/j.pbi.2009.07.014

[29] Smeekens, S. and Hellmann, H.A. (2014) Sugar Sensing and Signaling in Plants. Frontier in Plant Sciences, 5, 113.

[30] Purcell, P.C., Smith, A.M. and Halhord, N.G. (1998) Antisense Expression of a Sucrose Non-Fermenting-1-Related Protein Kinase Sequence in Potato Results in Decreased Expression of Sucrose Synthase in Tubers and Loss of Sucrose-Inducibility of Sucrose Synthase Transcripts in Leaves. The Plant Journal, 14, 195-202. https://doi.org/10.1046/j.1365-313X.1998.00108.x

[31] Laurie, S., Mckibbin, R.S. and Halford, N.G. (2003) Antisense SNF1-Related (SnRK1) Protein Kinase Gene Represses Transient Activity of an $\alpha$-Amylase (a-Amy2) Gene Promoter in Cultured Wheat Embryos. Journal of Experimental Botany, 54, 739-747. https://doi.org/10.1093/jxb/erg085

[32] Lu, C.A., Lin, C.C., Lee, K.W., Chen, J.L., Huang, L.F., Ho, S.L., Liu, H.J., Hsing, Y.I. and Yu, S.M. (2007) The SnRK1A Protein Kinase Plays a Key Role in Sugar Signaling during Germination and Seedling Growth of Rice. The Plant Cell, 19, 2484-2499. https://doi.org/10.1105/tpc.105.037887

[33] Paul, M.J., Primavesi, L.F., Jhurreea, D. and Zhang, Y. (2008) Trehalose Metabolism and Signaling. Annual Review of Plant Biology, 59, 417-441. 
https://doi.org/10.1146/annurev.arplant.59.032607.092945

[34] Avonce, N., Leyman, B., Mascorro-Gallardo, J.O., Van Dijck, P., Thevelein, J.M. and Iturriaga, G. (2004) The Arabidopsis Trehalose-6-P Synthase AtTPS1 Gene Is a Regulator of Glucose, Abscisic Acid, and Stress Signaling. Plant Physiology, 136, 3649-3659. https://doi.org/10.1104/pp.104.052084

[35] Zhang, Y., Primavesi, L.F., Jhurreea, D., Andralojc, P.J., Mitchell, R.A., Powers, S.J., Schluepmann, H., Delatte, T., Wingler, A. and Paul, M.J. (2009) Inhibition of SNF1-Related Protein Kinase1 Activity and Regulation of Metabolic Pathways by Trehalose-6-Phosphate. Plant Physiology, 149, 1860-1871. https://doi.org/10.1104/pp.108.133934

[36] Murashige, T. and Skoog, F. (1962) A Revised Medium for Rapid Growth and Bioassays with Tobacco Tissue Cultures. Physiologia Plantarum, 15, 473-497. https://doi.org/10.1111/j.1399-3054.1962.tb08052.x

[37] Braford, M.M. (1976) A Rapid and Sensitive Method for the Quantification of Microgram Quantities of Protein Utilizing the Principle of Protein Dye Binding. Analytical Biochemistry, 112, 195-203.

[38] Mizoguchi, T., Gotoh, Y., Nishida, E., Yamaguchi-Shinozaki, K., Hayashida, N., Iwasaki, T., Kamada, H. and Shinozaki, K. (1994) Characterization of Two cDNAs that Encode MAP Kinase Homologues in Arabidopsis thaliana and Analysis of the Possible Role of Auxin in Activating Such Kinase Activities in Cultured Cells. The Plant Journal, 5, 111-122. https://doi.org/10.1046/j.1365-313X.1994.5010111.x

[39] Usami, S., Banno, H., Ito, Y., Nishihama, R. and Machida, Y. (1995) Cutting Activates a 46-Kilodalton Protein Kinase in Plants. Proceedings of the National Academy of Sciences of the United States of America, 92, 8660-8664. https://doi.org/10.1073/pnas.92.19.8660

[40] Uchimiya, H., Kidou, S.I., Shimazaki, T., Aotsuka, S., Takamatsu, S., Nishi, R., Hashimoto, H., Matsubayashi, Y., Kidou, N., Umeda, M. and Kato, A. (1992) Random Sequencing of cDNA Libraries Reveals a Variety of Expressed Genes in Cultured Cells of Rice (Oryza sativa L.). The Plant Journal, 2, 1005-1009. https://doi.org/10.1111/j.1365-313X.1992.01005.x

[41] Condit, C.M. and Meagher, R.B. (1987) Expression of a Gene Encoding a Glycine-Rich Protein in Petunia. Molecular Cell Biology, 7, 4273-4279.

https://doi.org/10.1128/MCB.7.12.4273

[42] Gómez, J., Sanchez-Martinez, D., Stiefel, R., Rigau, J., Puigdomènech, P. and Pagès, M. (1998) A Gene Induced by the Plant Hormone Abscisic Acid in Response to Water Stress Encodes a Glycine-Rich Protein. Nature, 334, 262-264. https://doi.org/10.1038/334262a0

[43] De Oliveira, D.E., Seurinck, J., Inzé, D., van Montagu, M. and Botterman, J. (1990) Differential Expression of Five Arabidopsis Genes Encoding Glycine-Rich Proteins. The Plant Cell, 2, 427-436. https://doi.org/10.1105/tpc.2.5.427

[44] Fang, R.X., Pang, Z., Gao, D.M., Mang, K.Q. and Chua, N.H. (1991) cDNA Sequence of a Virus-Inducible, Glycine-Rich Protein Gene from Rice. Plant Molecular Biology, 17, 1255-1257. https://doi.org/10.1007/BF00028742

[45] Cheng, S.H., Keller, B. and Condit, C.M. (1996) Common Occurrence of Homologues of Petunia Glycine-Rich Protein-1 among Plants. Plant Molecular Biology, 31, 163-168. https://doi.org/10.1007/BF00020616

[46] Showalter, A.M. (1993) Structure and Function of Plant Cell Wall Proteins. The Plant Cell, 5, 9-23. https://doi.org/10.1105/tpc.5.1.9

[47] Ringli, C., Keller, B. and Ryser, U. (2001) Glycine-Rich Proteins as Structural 
Components of Plant Cell Walls. Cellular and Molecular Life Sciences, 58, 1430-1441. https://doi.org/10.1007/PL00000786

[48] Pego, J.V., Weisbeek, P.T. and Smeekens, S.C.M. (1999) Mannose Inhibits Arabidopsis Germination via a Hexokinase-Mediated Step. Plant Physiology, 119, 1017-1024. https://doi.org/10.1104/pp.119.3.1017

[49] Sheen, J. (1993) Protein Phosphatase Activity Is Required for Light-Inducible Gene Expression in Maize. The EMBO Journal, 12, 3497-3505.

[50] Ehness, R., Ecker, M., Godt, D.E. and Roitsch, T. (1997) Glucose and Stress Independently Regulate Source and Sink Metabolism and Defense Mechanisms via Signal Transduction Pathways Involving Protein Phosphorylation. The Plant Cell, 9, 1825-1841. https://doi.org/10.1105/tpc.9.10.1825

[51] Kholodenko, B.N. (2006) Cell Signalling Dynamics in Time and Space. Nature Review Molecular Cell Biology, 7, 165-176. https://doi.org/10.1038/nrm1838 


\section{Supplementary}

Probe
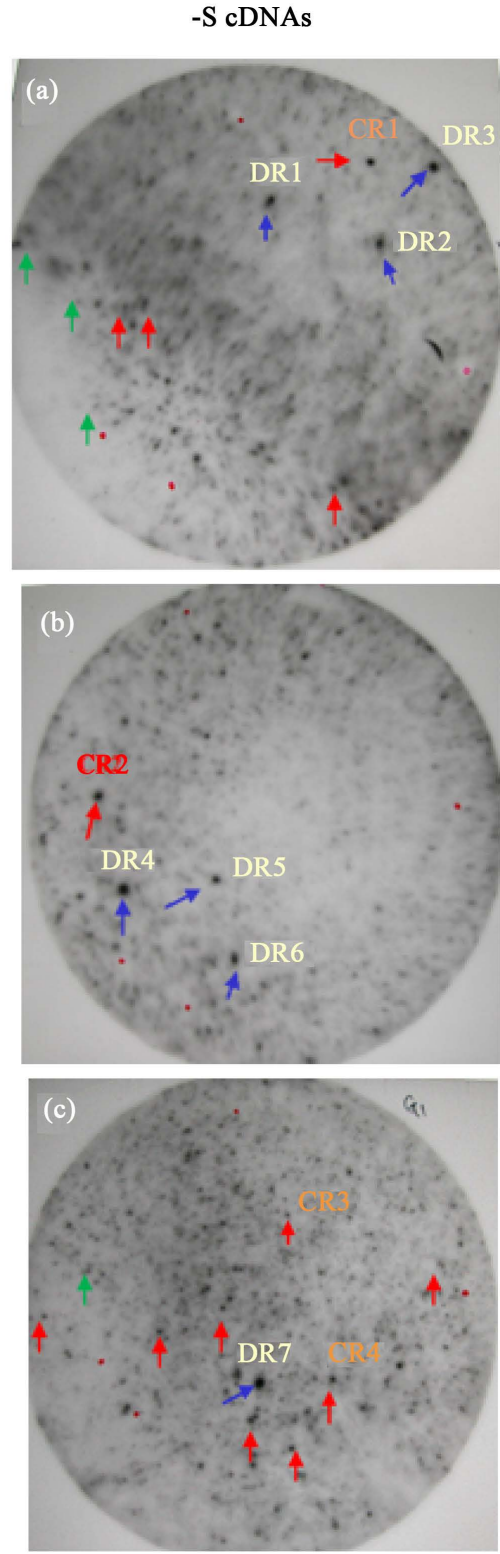

+S cDNAs
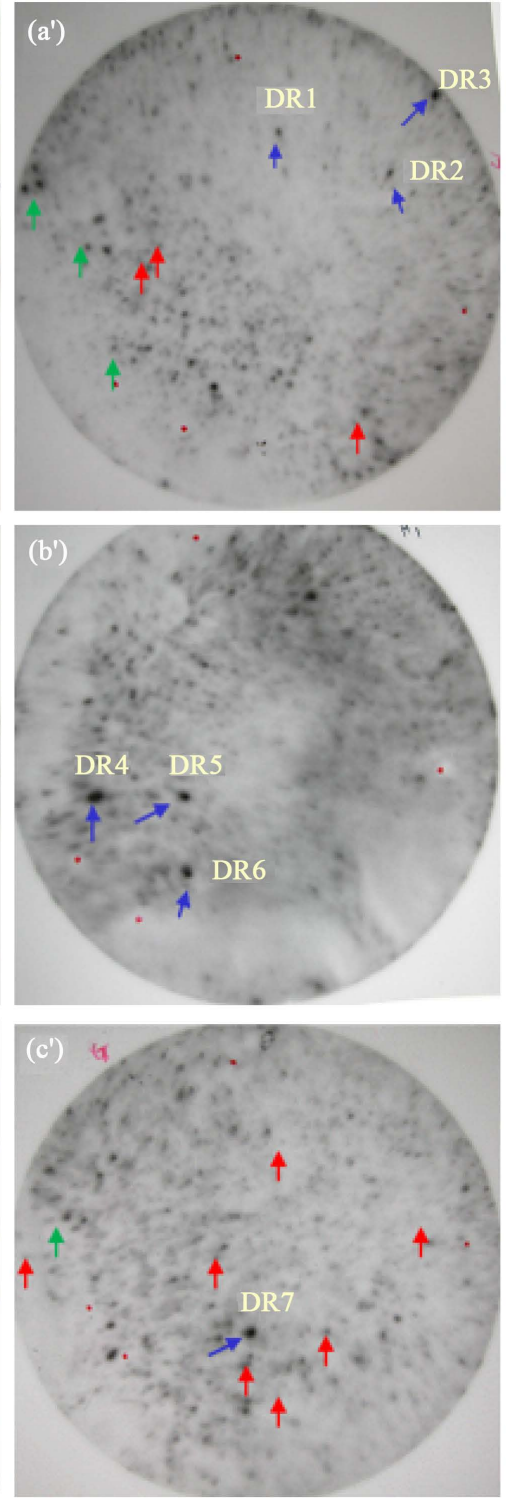

Figure S1. Differential screening to identify sugar-regulated genes. The cDNA library was constructed from rice suspension cells cultured under sugar starvation for $4 \mathrm{~h}$. The phage plaques from the library were plated and transferred to nylon filter membranes. Duplicate filters ((a) and (a'), (b) and (b'), and (c) and (c')) were hybridized with cDNA probes derived from mRNAs isolated from rice cells cultured in MS medium supplemented with (+S cDNAs, right panels; (a'), (b'), and (c')) or without (-S cDNAs, left panels; (a), (b) and (c)) sucrose for $24 \mathrm{~h}$. Red arrows indicate a strong hybridization signal expressed specifically in sugar-starved cells. Green arrows indicate a strong hybridization signal expressed specifically in sugar-containing cells. Blue arrows indicate the strong hybridization signals that were expressed constitutively in both sugar-containing and sugar-starved cells. 